\title{
Exploration and Analysis of the Problem of Colleges Teaching Management Information
}

\author{
Lili Liu ${ }^{1, a^{*}}$ and Xuehong Chang ${ }^{1, b}$, \\ 1 Jilin Agricultural University, Changchun , 130118, China \\ a 79856004@qq.com, b6 6614623@qq.com
}

Keywords: Higher Education; Information Construction; Network Security; Teaching Management

\begin{abstract}
Along with the development of information technology and the rapid development of the Internet, the educational information has become an important symbol of the educational modernization. In recent years, the relevant policies of the state have made it clear that the construction of educational information is an important task in the development of education in China. The teaching management information is an important aspect in the construction of educational information, Higher education is the cradle of cultivating talents, The teaching management information is especially important in higher education. Although the information management in modern colleges and universities has been spread gradually, but the overall level of information management in colleges and universities should be upgraded. According to the present situation and existing problems of college teaching management information, from infrastructure, network security, management system and personnel training aspects, this paper analyses and puts forward the corresponding construction measures of teaching management information.
\end{abstract}

\section{Introduction}

Teaching management plays an important role in the daily teaching work operation of Colleges and universities, the effect can't be ignored on promoting the construction and development of the universities, this work covers a wide range of aspects, involving student performance records, teaching arrangement, teaching management, and so on, the level of management affects the quality of teaching directly. With the number of students increasing, and the emergence of various new policies and new situation, the modern university must carry out meticulous management, the traditional concepts and methods need to be improved, the introduction of information technology, to achieve scientific and standardized management, which can improve the efficiency of teaching management and quality. In the current era, information construction is the only way for the development of colleges and universities, teaching management also need to achieve management information as soon as possible.

\section{The Importance of Colleges Teaching Management Information}

The Realization of Teaching Management Information Is the Particularity of Teaching Information and the Requirements of the Times. As everyone knows, the amount of information teaching management system in universities are very cumbersome and complex, including students' status as a student, the management of elective courses, teaching materials, examination and a variety of teaching information, the information is in a state of continuous updating, and is disorder, therefore, the processing is also very huge work. In order to meet the requirements of teaching management in the development of the times, there should be the need for a rapid and efficient management tools to help solve the huge work, this is the college teaching management information what we want to say here. Once the effective implementation of the teaching management information, many teaching management staff can greatly improve work efficiency, and save most time of the teaching management, and they can spend most of their time on teaching and research, then the management quality should be enhanced, the teaching reform should be further promoted.

The Realization of Teaching Management Information Is the Inevitable Requirement of Mass Education. Nearly 10 years of development in China's colleges, we can see that the size of 
the university has undergone tremendous changes, the number of students increased several times in this short period of ten years, the corresponding teaching workload management has become more and more huge and complex. In the process of teaching management, if you use traditional manual operation, then you will need huge human and material resources, and this model will lead to higher error rate. Therefore, the implementation of teaching management information has become an urgent problem for all colleges to solve.

To Realize the Information of Teaching Management Is Helpful to Improve Work Efficiency and Realize the Standardization and Scientific of Teaching Management. At present, many teaching managers are still in the state of experience management, and carry out the traditional management methods that old staff teach the new staff, No or no use of information management model, especially some of the older teaching managers still advocate for a piece of paper, a pen. Relying on these artificial methods for teaching resources collection, collation, analysis and statistics, these methods lead to low efficiency, repeated labor, workload, accuracy is low, Such as courses and examination arrangements management, if the lack of efficient and reliable software, the management is still dominated by manual operation, disorder and tedious work will cause a lot of waste personnel, also affect the process and quality of work, reduce the effect and function of teaching management. The reform of teaching management supported by information technology has great benefit in running schools. By realizing the high-speed sharing of information resources, it can promote the collaboration among departments and educational administration departments; Through electronic documents, paperless and information technology, teaching management can be programmed, standardized and scientific, so as to improve work efficiency and management level.

The Realization of Teaching Management Information Will Help to Speed up the Two-way Communication between Teaching Managers with Teachers and Students. With an appropriate analogy is the teaching management is the link between teachers and students to contact, In order to improve teaching methods and improve teaching quality, they must be timely access to the teaching process of information, two-way communication and feedback between teachers and students. To realize the information of teaching management, teachers and students can communicate directly with the teaching administrators through the network's timeliness, vitality and flexibility. This not only improves the accuracy of the opinions, but also speeds up the work process.

\section{The Current Situation and Existing Problems of Colleges Information Construction in China}

With the development of science and technology, all aspects of people's life and work have benefited from science and technology, especially the development of modern computer network technology, which makes our life and work more efficient and vivid. At present, the level of teaching management and teaching quality in Colleges in China have greatly benefited from the development of computer network technology, which makes the teaching management of colleges become more convenient and efficient. Because of the development of computer network technology application time is not long, the relevant personnel also lack a deep understanding of science, the technology and many needs should be improved in some places, so there are still many problems in the application of teaching management information in colleges.

Lacking Advanced Teaching Management concepts. By the long-term influence of the traditional idea of teaching management, teaching management work of colleges in the current there is widespread lack of awareness of the problem of information construction, the old teaching management concepts still are applied to the modernization teaching management. Although, because of modern technology shocks, many universities have begun to change the concepts of teaching management, but because the managers do not know fully and profoundly, resulting in a lack of the overall standard of teaching resources, such as the phenomenon that only pay attention to improving the hardware devices, these phenomena lead to the information management function is not get the real and full play.

The Information Level of Teaching Management Is Limited. Far as the current situation is concerned, there is a lack of timely updating part of the curriculum in colleges, especially there is 
only a small proportion of information courses in some traditional majors curriculum, For the non-computer professional students, although the colleges also opened some basic courses related in computer according with the requirements of national, but there was a serious lack of information courses, just do some specious writing to meet up, this situation leads to the modern information society development deviated from the requirements. At the same time, the network and intelligence of administrative management have not been popularized in the teaching management. Many work still needs manual operation, and the efficiency is low. Although the management information system software has been applied in universities, curriculum arrangement and examination management also can be realized by using the software, but there is a problem that information can be not shared, it also requires a lot of manual intervention. So the efficiency is low.

Teaching Managers Lack High Level of Information Management Ability. The teaching management staff is very important in the process of teaching management information, the realization of teaching management information requires that the relevant teaching management personnel should have high standard of the information technology ability, but in fact most of the teaching management staff has merely the application ability of simple text operation and report processing, ability is limited, many functions are not fully used and played, which also makes the process of teaching management information in colleges has been seriously hindered.

\section{The Measures and Countermeasures for Improving the Information Level of Teaching Management in College}

Improving Infrastructure and maintaining network security. Computer and network are the foundation of information management, for the teaching management department, they are responsible for the management of the teaching affairs of the whole school usually through establishing the official website and purchasing professional software. With the popularization of Internet technology, campus network has achieved full coverage of campus, and the teaching buildings, dormitory buildings, workers' areas and other areas can basically be networked. However, there are still many colleges, their infrastructure construction is incomplete, the students' dormitory has not yet been covered by the Internet, and wireless network speed is poor, it is inconvenient for students to access the internet. This requires colleges should pay more attention to this aspect, and give sufficient funds and manpower to further improve the network infrastructure construction.

As the main hardware equipment, computer replacement speed is very fast, colleges should also replace new products in time, and the old computer needs to be dealt with as soon as possible. Teaching management is very complex, often responsible for tens of thousands of information, data storage, query, call, which requires the speed of the computer is extremely high, there must be no crashes at work, or the information is likely to be lost or stolen. For example, the students choose courses online, teacher evaluation, or teachers concentrated entry scores, educational management system load is great, which put forward higher requirements for both hardware and software.

Software mainly refers to the educational management system, most colleges choose to buy systems from software companies, but should avoid falling into two misunderstandings. First, the system cannot be used forever. Some educational administrators believe that after the purchase of the system, you can only operate in accordance with the process. In fact, because the school has more and more problems, for example, excellent teacher training program, student transfer of professional, school enterprise joint school, and so on, the entire teaching management is facing a constantly changing environment, information management systems should also be improved to adapt to changes. So college teaching management department need to update the software regularly and add new modules. Second, the information management system is too rigid, and lack of contact with the school educational administration. For this aspect, the school can communicate with the software company in advance, organize software technicians to study and practice in the school, and develop more suitable system software according to the specific situation. Or arrange the excellent staff of our school to learn the technology from the software company and train the internal technical personnel.

In addition, in order to prevent the emergence of student files, information, information leakage, 
tampering and other circumstances, we must strengthen network maintenance, to ensure network security and stability. The Internet facilitates people's contact and information sharing, but its openness also brings a lot of problems, such as hacker attacks, Trojan horses and so on. This requires professional and technical personnel responsible for the installation of firewalls, updates patches, the use of encryption technology, critical information must be prepared to backup.

Changing Management Concept and Improving Management System. The idea is prior to the action, and the traditional teaching management mainly depends on manual management. The tasks are heavy, efficiency is low, and this method is prone to omissions, repetition, mistakes and so on. Search queries are extremely difficult in the face of large amounts of information. The computer network times have pointed out the new direction for teaching management, this also is the only way for the modern education management, which requires the college management personnel to renew the idea, accept the new thing positively. Managers need to broaden their horizons and foster awareness of innovation from a long-term perspective, Although there will be various adaptations in the process of replacing the old with the new, in order to improve the management level of the teaching and promote the long-term development of the school, it is imperative to make constant progress and strengthen cooperation with all sides.

Talent is the key to competition in the era of knowledge economy. The management of colleges should also change management concept and implement humanized management. With the deepening of the reform of quality education, more and more attention has been paid to the humanistic concept. Although the educational administration system is just a management software, it should not be too mechanized, but it should reflect human nature and personality. For example, the system is opened to all teachers and students, it should be facilitate operation, so the students can log on view relevant information at any time. It is necessary to adjust the functions of teaching administrators so as to strengthen their awareness of service and provide high quality services for teachers and students and for teaching management.

Educational administration information system is the core of modern teaching management, but only system software is far from enough, because in some ways, the system is only a supplementary tool, and the actual management is more complex, which requires a sound and feasible management system, in order to play the role of the information systems. Teaching supervision team should be established, which responses for the supervision and management system development and daily administration, implement the responsibility system, a clear division of responsibilities of various departments, streamline internal mechanism, optimize work flow, improve the overall management efficiency. The team members should be managed by the school management, the teaching management department, the Department and some teachers. It can not only realize the information exchange, but also ensure the fairness and objectivity of the supervision work.

Attaching Importance to Personnel Training and Improving Personnel Quality. Whether it is the implementation of the system, or the use of hardware and software, all of these are operated by people, so the teaching management staff's professional skills and comprehensive quality is very critical. It has already been noticed, during the development of the educational information management system, in order to prevent system failures and other accidents, the colleges can develop an excellent quality and high technical personnel in the interior, management personnel can also be hired from the outside, so that the problem of the management system can be solved in time.

After determining the educational management personnel, we should also pay attention to its management and application, consider that the daily work is boring, and the workload is greater, managers maybe lack motivation. In this regard, it is possible to improve treatment, increase welfare, give more humane care, organize recreational activities, and help managers relieve their stress. Especially the new recruits, it takes a period of time to learn and be familiar with the business, should try to retain, avoid frequent mobilization.

In addition, the teaching management staff requirements are very high, in addition to familiar with the management content, but also have good information literacy, as well as good professional ethics. Schools should regularly conduct training to management personnel, they can learn computer skills, and understand the latest features of the software, teaching management staff 
should have an opportunity to observe and study every year, and be arranged a comprehensive assessment at the end of the year. The system of rewards and punishments should be implemented to stimulate the initiative of managers and reward those who perform is well.

Achieving Resource Sharing, Playing System Functions. Teaching management involves all aspects of the school, in addition to teaching management staff, other departments should take the initiative to participate in it, and achieve information sharing. For example, when inputting student payment information, you must contact the finance department. If students transfer to a major, you need to contact the college and update the information of the database in time. At present, many colleges attach great importance to cooperation with enterprises and external universities. They can learn from each other's strengths and complement each other, and also need to share information resources.

Educational management information system should be properly divided into modules to facilitate management and maximize its role. For example, the teaching management module should mainly include the construction of curriculum library, enrollment plan, training program for outstanding teachers, etc. The teaching material management module including materials procurement, storage, ordering, payment, transfer, exchange, stock and loss etc. The system should provide ISBN information machine-readable recognition function, the system comprehensive management of teaching materials into the library, teachers and students receive the details of the teaching materials. The practical teaching module mainly includes practice experiment teaching, project design, graduation project and so on.

\section{Conclusion}

The teaching management information system is a product of the information age, but also the inevitable choice of modern university management, information management, reduces the labor, the management efficiency and quality has improved significantly, the teaching level has been greatly improved. In the future teaching management, we should renew the management concept, strengthen the infrastructure construction, train an excellent team of talents, formulate a reasonable management system, and form a relatively complete information management system.

\section{Reference}

[1] Y.P.Liu and J.Y.Wang: Journal of Baotou Medical College, (2010 ) No.12.(In Chinese)

[2] T.T.Zhang ; Heilongjiang Science and Technology Information, (2010 ) No.09.(In Chinese)

[3] J.Zheng: Science and Technology Pioneering Monthly Magazine, (2009 ) No.08.(In Chinese)

[4] G.L.Zhang : China Electronic Commerce, (2013 ) No.22,p.55.(In Chinese)

[5] Y.L.Li and Y.He: Education and Profession, (2013 ) No.35,p.43-44.(In Chinese)

[6] C.J.Song: Science Studies. (2013) No.28,p.171-172.(In Chinese)

[7] X.Y.Hu and N.Xue: Science and Wealth, (2013 ) No.27,p.25.(In Chinese)

[8] R.L.Wang: Science and Technology Perspective, (2014) No.20, p168. (In Chinese)

[9] S.M.Tang: Fujian Computer, (2011) No.27 p.149-150. (In Chinese)

[10] Z.H.Li: Modern Enterprise Education, (2012) No.41 p.92. (In Chinese) 